\title{
Atividades investigativas de ensino: mediação entre ensino, aprendizagem e formação docente em Ciências
}

\section{Research activities of teaching: mediation between teaching, learning and teaching training in Sciences}

\author{
Maria Nizete Azevedo ${ }^{1}$ \\ https://orcid.org/0000-0002-6827-9963 \\ Maria Lúcia Vital Santos Abib ${ }^{2}$ \\ https://orcid.org/0000-0001-9337-0067 \\ Leonardo André Testoni ${ }^{1}$ \\ https://orcid.org/0000-0001-9140-4788
}

\begin{abstract}
Resumo: Neste trabalho, de escopo teórico, discute-se os conceitos de Atividade Investigativa de Ensino (AIE) e de Atividade Investigativa de Aprendizagem (AIA), a partir da articulação entre resultados de pesquisas realizadas pelos autores, e fundamentos da Teoria Histórico-Cultural. Em linhas gerais, uma AIE consiste em um movimento colaborativo entre docentes, na busca por resolver problemas de ensino por meio da elaboração de AIA, seu desenvolvimento junto aos estudantes, bem como reflexões e análises sobre os resultados observados. Focaliza-se conceitualmente uma AIE, como modos de aprendizagem da docência no curso de sua realização e modos de aprendizagem e de apropriação de conhecimentos possibilitados aos estudantes inseridos em uma AIA. Conclui-se que o estudo reforçou o caráter de organização do ensino, mediação e formação docente da AIE, dado o seu papel na unidade entre processos de ensino e de aprendizagem, na construção da atividade docente como práxis e, como tal, propulsora de desenvolvimento profissional.
\end{abstract}

Palavras-chave: Ensino de ciências. Atividade investigativa de ensino. Atividade investigativa de aprendizagem. Educação científica. Formação de professores.

\begin{abstract}
In this theoretical work, we discuss the concepts of investigative activity of teaching (IAT) and the investigative activity of learning (IAL), based on the articulation between results of research carried out by the authors and foundations of Cultural Historical Theory. An IAT consists of a collaborative movement among teachers, in the search to solve teaching problems through the elaboration of IAT, their development with their students and reflections / analysis on observed results. We focus conceptually an IAT, modes of learning of teaching in the course of its realization and modes of learning and appropriation of knowledge made possible to the students inserted in an ICL. As a conclusion, we consider that this study reinforced the organizational character of teaching, mediation and teacher training of the IAT, given its role in the unity between teaching and learning processes, in the construction of teaching activity as praxis and, as such, propelling professional development.
\end{abstract}

Keywords: Science teaching. Investigative activity of teaching. Investigative activity of learning. Teacher training. Scientific education.

\footnotetext{
${ }^{1}$ Universidade Federal de São Paulo (UNIFESP), São Paulo, SP, Brasil. E-mail: <maria.nizete@unifesp.br>.

${ }^{2}$ Universidade de São Paulo (USP), Faculdade de Educação, São Paulo, SP, Brasil.
} 


\section{Introdução}

Crianças e professora sentadas em círculo conversam sobre o corpo de uma formiga recém-vista ao estereomicroscópio com aumento de 40x. Palavra vai, palavra vem, uma das crianças enuncia uma pergunta: “- Prô, por que a formiga, com seis perninhas, consegue subir na parede, e nós, com duas, não conseguimos?"3

Uma pergunta autêntica destaca-se em uma conversação entre professora e crianças - autêntica porque quem pergunta não sabe e pergunta porque quer saber. Esta é uma cena representativa de uma ação que faz parte de uma Atividade Investigativa de Aprendizagem (AIA), por meio da qual determinado professor medeia um movimento dialógico entre estudantes que resolvem problemas de aprendizagem para se apropriarem de conhecimentos científicos. Essa atividade de aprendizagem, por sua vez, foi elaborada por professores em Atividade Investigativa de Ensino (AIE).

A partir de revisões teóricas e de resultados de investigações nas áreas de ensino de ciências e formação de professores realizadas pelos autores, pautamos o conceito de Atividade Investigativa de Ensino (AIE). A discussão proposta é situada na abrangência do conceito de atividade, por sua vez, concebido como unidade do desenvolvimento humano, e no âmbito da relevância atribuída ao papel da investigação, tanto para a aprendizagem na área de educação em ciências, como para o aprimoramento profissional de professores.

O papel da educação escolar ganha destaque no corpo deste trabalho, por pressupor-se a potencialidade de atividades educativas na mediação de relações entre o educando e a produção social e cultural historicamente acumulada pela humanidade. Nessa dimensão, o papel da escola também se sobressai

[...] como espaço de aprendizagem e apropriação da cultura humana elaborada, bem como do modo de prover os indivíduos, metodologicamente de formas de apropriação e criação de ferramentas simbólicas para o desenvolvimento pleno de suas potencialidades (MOURA et al., 2010, p. 207-208).

O conceito de Atividade Investigativa de Ensino (AIE) articulado aos princípios da educação humanizadora e da escola como espaço de aprendizagem e de apropriação da cultura, torna-se elemento mediador e organizador do ensino e da aprendizagem. Na realização de uma AIE, atividade de ensino e atividade de aprendizagem são processos interdependentes, de modo a articular o quê e o como ensinar com o quê e o como aprender dos sujeitos envolvidos - professor e estudantes (AZEVEDO, 2013a). Diante de tais pressupostos, orientamos a discussão proposta a partir das seguintes questões: como se estrutura uma AIE para que apresente esse potencial organizativo e formativo?; quais modos de aprendizagem e de aprimoramento docente podem ser proporcionados ao professor no processo de realização de uma AIE?; quais modos de aprendizagem e de apropriação de conhecimentos científicos são possibilitados aos estudantes ao se inserirem em uma AIA?

\footnotetext{
${ }^{3}$ Informação de 2014 fornecida pela autora Maria Nizete Azevedo, de seus arquivos e entrevistas pessoais.
} 
São questões tão complexas quanto fundamentais, aqui abordadas em suas premissas essenciais. De início, pontuamos o conceito de atividade em sua gênese histórica, para, em seguida, relacioná-lo aos elementos teóricos e metodológicos que estruturam uma Atividade Investigativa de Ensino. Mais adiante, discutimos processos de aprendizagem do professor e do estudante inseridos, cada qual, em sua atividade, mas sem perder de vista a interdependência entre as atividades e seus sujeitos. Essa discussão é ilustrada com cenas representativas de ações de Atividades Investigativas de Ensino, cujos dados são alçados de pesquisas anteriores e do banco de dados formado pelos autores por ocasião de suas coletas no curso de suas investigações. A intenção é criar condições para uma melhor visualização e compreensão das relações estabelecidas entre os sujeitos envolvidos, bem como das possibilidades de aprendizagem gestadas na prática da atividade.

\section{O conceito de Atividade}

No arremesso certeiro, vai sempre um pouco de quem atira. (COUTO, 2013, p. 25).

O conceito de atividade é fundamentado a partir de pressupostos da Teoria HistóricoCultural. Com base nesse aporte teórico, a atividade tem sua gênese no conceito de trabalho tal qual é definido nas teses marxistas. Trabalho, que se traduz em atividade humana e deriva do intercâmbio entre o homem e a natureza, o qual se constitui essencialmente como atividade mediada. Numa atividade mediada, as relações estabelecidas entre o sujeito e o seu objeto de atuação não são diretas e imediatas, mas interpostas por instrumentos e signos (VIGOTSKI, 2009). Os resultados ou produtos decorrentes dessa atuação têm em si materializado a essência humana e material presentes na relação.

$\mathrm{Na}$ totalidade do processo de realização do trabalho, corpo e mente humanos são postos em movimento. O produto do trabalho incorpora essa natureza humana, ou seja, esforços físicos e mentais são objetivados e exteriorizados no instrumento produzido. À guisa de exemplos, podemos lembrar que celulares, medicamentos, quadros de arte, lápis, entre tantos instrumentos, são produtos do trabalho humano, e como tal, guardam em si a marca humana. Para aclarar, podemos nos perguntar: por que o lápis se acomoda tão bem nas mãos humanas? Por que o lápis é composto da madeira e de grafite? Se parássemos um pouco para analisar esse objeto, veríamos nele as marcas da necessidade humana que impeliu a sua criação; veríamos também, ainda que de modo abstrato, o conjunto de conhecimentos imanentes aos atos humanos necessários ao seu planejamento e produção. Se apurássemos um pouco mais o nosso olhar, nos atentaríamos para a história desse objeto e nos daríamos conta de que um simples lápis tem em si incorporado não apenas a experiência dos trabalhadores que ora o produz e nem a satisfação da necessidade do atual escritor, mas experiências e conhecimentos cumulativos de gerações precedentes. Antes de se tornar a atual lapiseira com refil de grafite, o nosso lápis foi vara de rabiscar, pequenos pincéis, até tornar-se um pedaço de metal fino ou stillus usado na escrita dos papiros.

Em síntese, o lápis, em qualquer período da história da humanidade, tem em si incorporado, ou em si objetivado, marcas do homem que o planejou e o produziu; incorporações, por sua vez, transferidas às futuras gerações pelo próprio processo de produção e criação. 
Tal como afirma Sánchez Vázquez (2007, p. 129), o homem “[...] é por excelência um ser que necessita objetivar-se de um modo prático, material, produzindo, assim, um mundo humano". Significa dizer que a produção de instrumentos, orientada para a satisfação de necessidades, marca a trajetória humana no planeta Terra e responde pelo acúmulo do patrimônio histórico da humanidade.

Por meio do trabalho, como atividade humana, os homens, a um só tempo, transformam a natureza para satisfazer suas necessidades materiais e psicológicas e se autotransformam, desenvolvendo faculdades especificamente humanas. Karl Marx (MARX, 1985, p. 149) escreve:

Antes de tudo, o trabalho é um processo entre o homem e a Natureza, é um processo em que o homem, por sua própria ação, medeia, regula, e controla seu metabolismo com a Natureza. [...] Ele põe em movimento as forças naturais pertencentes à sua corporalidade, braços e pernas, cabeça e mão, a fim de apropriar-se da matéria natural numa forma útil para sua própria vida. Ao atuar, por meio desse movimento sobre a natureza externa a ele e ao modificá-la, ele modifica, ao mesmo tempo, sua própria natureza.

Nessa compreensão, o desenvolvimento humano resulta da atividade do trabalho, o que confere a essa categoria o caráter transformador e criador. Trabalho traduz-se em práxis, na inseparabilidade entre a atividade teórica e a atividade prática, entre a atividade de planejamento e de produção, sem que uma se contraponha a outra. Para Kosik (1976), a práxis é mais que a articulação teoria/prática: em sua interpretação do materialismo histórico e dialético, a práxis consiste na própria existência humana, na totalidade do ser humano, produzida historicamente: "A práxis é ativa, é atividade que se produz historicamente - quer dizer, que se renova continuamente e se constitui praticamente -, unidade do homem, do mundo, da matéria e do espírito, do sujeito e do objeto, do produto e da produtividade" (KOSIK, 1976, p. 202, grifo do autor).

Kosik (1976, p. 204, grifo do autor) enfatiza o caráter de totalidade da práxis, ao imprimir no conceito de trabalho o "momento existencial", sem o qual não se constituiria em práxis:

Assim, a práxis compreende - além do momento laborativo - também o momento existencial: ela se manifesta tanto na atividade objetiva do homem, que transforma a natureza e marca com sentido humano os materiais naturais, como na formação da subjetividade humana, na qual os momentos existenciais como a angústia, a náusea, o medo, a alegria, o riso, a esperança não se apresentam como "experiência" passiva, mas como parte da luta pelo reconhecimento, isto é, do processo de realização da liberdade humana. Sem o momento existencial, o trabalho deixaria de ser parte da práxis.

Essa dimensão da práxis conduz a uma melhor compreensão da relação entre trabalho/ práxis e o desenvolvimento humano, a qual atribui-se sentidos com conteúdos contrários ao da alienação, exatamente por presumir a atividade laborativa, em que se tem domínio sobre o processo e o produto do trabalho, sem a dicotomia homem/trabalhador: aquele que realiza a atividade laboral é o mesmo homem que chora e sorri em suas agruras e alegrias cotidianas. 
Seus momentos existenciais, junto às suas condições de trabalho não alienado, criam condições para o seu desenvolvimento humano e profissional.

No trabalho, em condições de alienação, esse desenvolvimento é obstaculizado por subtrair do sujeito o ato da concepção, instrumentos e signos teóricos, bem como a plenitude de sua subjetividade. Marcas dessas condições são visíveis na atual situação de precarização imposta à profissão docente, a qual afasta cada vez mais o professor de meios materiais e subjetivos para exercer a sua atividade laboral. Baixos salários, impossibilidade de planejamentos e de reflexões individuais e coletivas são exemplos de elementos que favorecem a ruptura entre anseios subjetivos do sujeito professor e a função social de sua profissão, o que pode culminar em um quadro social de alienação oposto ao conceito de atividade ou práxis aqui fundamentado (AZEVEDO, 2013b).

O conceito de atividade é redimensionado na obra de Vigotski (2009) como elemento essencial na formação da consciência e, como princípio fundante, inspira Leontiev (1978, p. 68) na elaboração da Teoria da Atividade. Na abrangência dessa teoria, atividade não é compreendida como qualquer processo, mas "[...] apenas aqueles processos que, realizando as relações do homem com o mundo, satisfazem uma necessidade especial correspondente a ele”. Assim, uma atividade origina-se de uma necessidade do sujeito, que a realiza com o intuito de satisfazê-la.

Essa necessidade torna-se o motivo que impele o sujeito a agir. O motivo assume um papel fundamental na estrutura da atividade, o qual contempla o próprio objetivo. Leontiev (1983, p. 83) diz que "o objeto [objetivo] da atividade é o seu motivo real". Portanto, em uma atividade, objetivo e motivo são coincidentes ou correspondentes, o que significa dizer que um sujeito está em uma determinada atividade quando o motivo que o impele coincide com o objetivo da mesma, ou seja, há uma coincidência entre o propósito da atividade com aquilo para o qual as suas ações se dirigem. Por exemplo, diríamos que determinado professor está em atividade se o motivo que o impele a realizar o seu ofício de ensinar coincidir com o objetivo da atividade educativa definido socialmente - o de promover a apropriação de conhecimentos. Atividade, portanto, assumiria a mesma dimensão da práxis. Como disse Kosik (1976), práxis é atividade.

Além da necessidade, do motivo e objetivo, uma atividade estrutura-se em ações e operações. Desencadeada pelo motivo, a atividade é posta em movimento por um conjunto de ações relacionadas entre si, orientadas e estimuladas pelo objetivo geral da atividade. Vale esclarecer que a atividade ou práxis não se circunscreve a apenas um sujeito isolado, mas assume caráter coletivo. $\mathrm{O}$ sujeito em atividade, impelido pelo seu motivo, realiza ações com objetivos próprios, mas orientados pela necessidade coletiva de resolver problemas intrínsecos ao objetivo que rege a unidade do coletivo, o qual unifica os sujeitos em busca do objeto comum.

Nessa linha de pensamento, podemos pensar a escola como um conjunto de atividades, cada qual com suas ações e operações a ela subordinadas, mas unificadas pelo objetivo comum - o de garantir a aprendizagem e apropriação de conhecimentos pelos estudantes. Afinal, essa é a função social da instituição escolar, reconhecida historicamente.

Uma dessas atividades pode ser, por exemplo, a de ensinar determinado conceito científico, posta em prática por ações, tais como proporcionar a resolução de problemas de cunho experimental, criar oportunidades de leituras e escritas ou de garantir conversações entre os estudantes. Essas ações são impelidas por motivos/objetivos direcionados para o cumprimento do objetivo da atividade da qual fazem parte. Por sua vez, cada ação é realizada por diferentes 
operações. A ação de proporcionar a resolução de problemas de cunho experimental, por exemplo, pode ser realizada por meio de muitas operações condicionadas às condições concretas de execução, a começar pela organização do espaço da sala de aula, seleção do material a ser utilizado, enunciação do problema a ser resolvido, entre tantas outras.

\section{O conceito de Atividade Investigativa de Ensino (AIE)}

Conferimos ao conceito de atividade o mesmo que lhe é atribuído por Leontiev (1978), na Teoria da Atividade. A Atividade Investigativa de Ensino é orientada por um determinado motivo/objetivo e realizada por um conjunto de ações e operações com objetivos próprios, mas correlacionados ao objetivo da atividade da qual fazem parte. Relacionamos o conceito AIE como um processo que unifica a atividade pedagógica, formação e desenvolvimento profissional docente e aprendizagem dos estudantes. Essa unidade aproxima a AIE da construção da atividade docente como atividade humana ou práxis. Vejamos a seguir como uma AIE é estruturada para que apresente tais possibilidades.

A resolução de problemas, gerados pelo desejo de ensinar aos alunos, é a essência que orienta a organização do ensino e da aprendizagem dos sujeitos em atividade investigativa de ensino. Professores em coletivo, imbuídos pelo motivo de criar situações de aprendizagem, a partir do seu contexto de trabalho e do Projeto Político Pedagógico, discutem sobre suas dificuldades e necessidades e as transformam em problemas de ensino. Com clareza desse problema, do objetivo e do motivo que os mobilizam, planejam ações em busca de soluções e do alcance do objetivo. De modo geral, consiste em um movimento composto pela articulação entre as ações de planejamento, desenvolvimento em sala de aula e reflexões sobre os resultados observados. Essas ações circunscrevem-se em um ciclo aberto, pois o ato de refletir pode gerar novos problemas e o reinício de novos ciclos.

A busca de soluções para o problema de ensino gera um conjunto de ações planejado pelos professores para ser realizado pelo estudante. Em outras palavras, os professores elaboram seus planos de ensino, que podem se caracterizar, em determinadas condições, por atividades de caráter investigativo, que se constitui como uma das ênfases possíveis para o ensino de ciências. Ao conjunto de ações a ser desenvolvido pelos alunos em sala de aula e derivado, chamamos de Atividade Investigativa de Aprendizagem (AIA), por sua vez orientada por um problema de aprendizagem, cuja solução levará os estudantes à apropriação de conhecimentos científicos.

Para melhor compreensão, vamos visualizar as duas atividades - AIE e AIA -, nos esquemas representados na Figura 1.

As atividades de ensino e de aprendizagem são distintas entre si a considerar: o sujeito que a põe em prática; o conteúdo do objetivo e do motivo que impele o sujeito a agir; o conteúdo do problema que desencadeia as diferentes ações e operações, as quais guardam suas peculiaridades em cada atividade.

Como podemos verificar no esquema da atividade investigativa de ensino, o sujeito é o professor - o motivo/objetivo que o impele origina-se de sua necessidade de ensinar de modo a proporcionar a aprendizagem de seus alunos. Todas as ações de planejamento e desenvolvimento e reflexão buscam cumprir esse objetivo. A atividade investigativa de aprendizagem (AIA) é desencadeada pelo problema de aprendizagem, o qual conduz o estudante a planejar ações para resolvê-lo. Essas ações são estratégias de investigação, de diferentes naturezas, podendo ser de 
cunho experimental ou diferenciadas, como saída a campo, entrevistas, entre outras. Rodas de conversa, escrita de relatórios e leituras são exemplos de ações organizadas pelo professor para concluir e finalizar a atividade de aprendizagem.

Figura 1. Relação ensino-aprendizagem

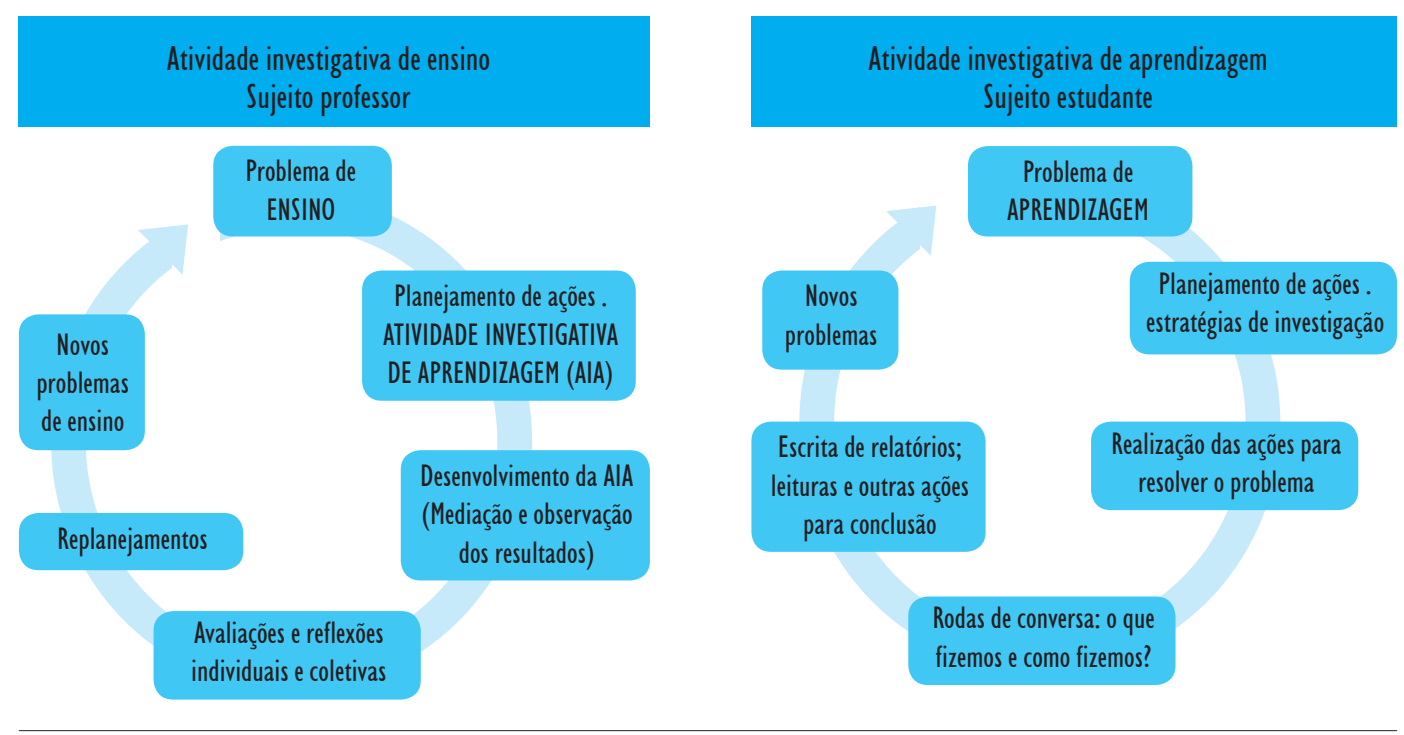

Fonte: elaborado pelos autores.

Para ficar mais claro, vamos supor que um grupo de professores deseja ensinar sobre os animais para crianças do primeiro ano de escolarização. Diante dessa escolha temática, passam a delimitar os conteúdos a serem abordados e decidem tomar como ponto de partida o estudo dos animais que habitam a escola. De acordo com essa decisão, elaboram o problema de ensino, o qual poderia ser: como ensinar sobre os animais, suas características anatômicas e fisiológicas, para crianças do primeiro ano de escolarização? (AZEVEDO et al., 2005). Encerram-se, nessa questão, o motivo do coletivo docente e o objetivo da atividade, quais sejam criar situações de aprendizagem para possibilitar que os pequenos estudantes saibam observar e diferenciar os animais entre si, bem como discutir seus modos de locomoção, alimentação, defesa, entre outras funções.

O próximo passo seria a elaboração do problema de aprendizagem - uma questão ou situação desencadeadora capaz de colocar os estudantes em atividade. Esse problema, poderia ser assim formulado: quais animais você acha que habitam o quintal da escola?; Como faremos para saber se os animais listados por vocês, de fato, habitam esse espaço? Com esse problema elaborado, o coletivo planeja as ações dele decorrentes, como uma saída a campo, por exemplo, e inicia-se o processo de desenvolvimento em sala de aula. (AZEVEDO et al., 2005). 
Esclarecemos, ainda, que o problema, seja de ensino ou de aprendizagem, não é uma pergunta qualquer, mas uma questão ou uma situação desencadeadora, cuja resposta desconhecida, requer a mobilização do sujeito que a deseja conhecer. Como escreve Saviani (1996, p. 13, grifos nossos),

[...] uma questão em si não caracteriza o problema, nem mesmo aquela cuja resposta é desconhecida; mas uma questão cuja resposta se desconhece e necessita conhecer, eis aí um problema. Algo que eu não sei não é problema; mas quando eu ignoro alguma coisa que eu preciso saber, eis-me, então, diante de um problema.

Moura (2000, p. 35) assinala que na atividade o problema é do sujeito, porque se origina de necessidades próprias. No ínterim dessa atividade, a busca de soluções permite ao sujeito um avanço do conhecimento "[...] por meio do processo de análise e síntese e lhe permite desenvolver a capacidade de lidar com outros conhecimentos a partir dos conhecimentos que vai adquirindo à medida que desenvolve a sua capacidade de resolver problemas".

Apesar da distinção que há entre a atividade de ensino e de aprendizagem, são processos interdependentes entre si. A atividade de ensinar realiza-se com e para a atividade de aprender; uma não existe sem a outra; uma gesta o motivo da outra e vice versa; o motivo do professor ganha sentido e se realiza no motivo do aluno; o professor realiza seu motivo de ensinar no planejamento e mediação das ações de aprendizagem dos alunos. Nas palavras de Moura et al. (2010, p. 216):

As ações do professor na organização do ensino devem criar, no estudante, a necessidade do conceito, fazendo coincidir os motivos da atividade com o objeto de estudo. O professor, como aquele que concretiza objetivos sociais objetivados no currículo escolar, organiza o ensino: define ações, elege instrumentos e avalia o processo de ensino e aprendizagem.

Moura et al. (2010), além de pontuarem algumas ações docentes na atividade de ensino, enfatizam a intencionalidade dessas ações em gestar os motivos dos estudantes a fim de garantir que esses motivos sejam coincidentes com o objetivo da atividade desses sujeitos. Ações do professor são articuladas às ações dos estudantes, o que reforça a ideia de interdependência entre ensino e aprendizagem. A elaboração do problema de aprendizagem é orientada pelo motivo e objetivo do professor contidos no problema de ensino.

Vamos retornar à estrutura da atividade investigativa de ensino, no que diz respeito ao processo de mediação da realização da atividade investigativa de aprendizagem realizada pelos estudantes. Esse processo consiste na principal etapa de articulação entre o ensino e a aprendizagem - o professor ao mesmo tempo em que conduz e medeia as ações dos estudantes em sua atividade, observa atentamente os resultados para posterior análise e reflexão junto aos seus parceiros de trabalho. Reformulações e novos problemas podem surgir desse processo de avaliação individual e coletiva. Cada ação de avaliação e de replanejamento tem o potencial de gerar novas necessidades, novos conteúdos, novos motivos/objetivos e, por conseguinte, novos problemas de ensino e/ou de aprendizagem. Por exemplo, perguntas autênticas proferidas pelos 
estudantes na mediação/realização da AIA podem conter conteúdo epistemológico, o qual pode vir a se constituir no núcleo conceitual do novo problema de aprendizagem.

O prólogo deste trabalho pode ser um bom exemplo de pergunta proferida por uma criança, no curso do desenvolvimento da atividade sobre os animais que habitam a escola. De acordo com Azevedo et al. (2005), após visitar o quintal da escola e verificar quais animais habitam esse espaço, outras ações foram desenvolvidas pelos estudantes, como relatar aos colegas suas observações numa roda de conversa, produzir um relatório (produção espontânea com escrita e desenhos) e observar uma formiga morta ao estereomicroscópio. Exatamente após observar a formiga, um dos estudantes pergunta: "Prô, por que a formiga, com seis perninhas consegue subir na parede, e nós, com duas, não conseguimos??" . Coube ao coletivo avaliar o seu conteúdo epistemológico e elaborar um novo problema de aprendizagem.

Entretanto, convém destacar que nem toda pergunta autêntica é passível de transformação, pois há que se considerar a relação entre o conteúdo da pergunta e o conteúdo da atividade em curso. Ressaltamos que os ciclos de atividades são regidos por objetivos previamente elaborados pelos docentes, os quais regulam as escolhas e decisões sobre quais perguntas devem ser priorizadas. (AZEVEDO; ABIB, 2013).

A interdependência entre o ensino e a aprendizagem pode ser garantida na organização do ensino por atividades, o que, por sua vez, pode também se expressar na organização da docência por atividades, a qual ganha a possibilidade de se estabelecer como práxis. Em tal compreensão a AIE torna-se a unidade entre a teoria e a prática, a considerar o seu caráter coletivo e caminhos criados que levam à inseparabilidade entre a teoria e a prática; entre a objetividade e a subjetividade dos sujeitos envolvidos: uma ação desencadeia outra, não sendo mais possível diferenciar teoria e prática nelas incorporadas. A constante necessidade de delimitar o objeto de ensino/aprendizagem, planejar, elaborar e avaliar, requer estudos e pesquisas, que demandam novas elaborações. Assim, a AIE como práxis pedagógica vai se configurando como instrumento mediador do exercício cotidiano da docência repleto de relações mediadas, gestadas na atividade conjunta e no compartilhamento de conhecimentos. Nessa dimensão, a práxis pedagógica torna-se o núcleo organizativo e formativo não apenas por organizar a docência, mas também por estabelecê-la como fonte de aprendizagem dos sujeitos nela envolvidos. Na AIE, concebida como núcleo formativo, a aprendizagem do professor entrelaça-se à aprendizagem dos estudantes e vice versa.

\section{Sujeitos em aprendizagem na Atividade Investigativa de Ensino}

\section{Professores aprendem e se desenvolvem profissionalmente}

A discussão sobre aprendizagem da docência e desenvolvimento profissional do professor correlacionado ao exercício da docência, sendo esta organizada por atividade, é referenciada na premissa de que o desenvolvimento humano decorre do trabalho realizado como atividade humana, desencadeador de outras atividades (LEONTIEV, 1978). A docência realizada na perspectiva da práxis pedagógica pode gerar atividades de aprendizagem da docência e gestar um ambiente social com ações que impulsionam o desenvolvimento profissional

\footnotetext{
${ }^{4}$ Informação de 2014 fornecida pela autora Maria Nizete Azevedo, de suas entrevistas e arquivos pessoais.
} 
dos professores. Pressupõe-se que o professor se forma professor continuamente por meio de ações decorrentes do seu trabalho docente, constituídas na relação com seus pares e na busca por garantir a aprendizagem de seus alunos (AZEVEDO, 2013b). Coerente com as premissas marxistas, o professor autotransforma-se ao transformar o seu objeto de trabalho, isto é, ao garantir a apropriação de novos significados por seus alunos.

Sob tais premissas teóricas, retomamos a pergunta: quais modos de aprendizagem e desenvolvimento profissional docente e de aprimoramento docente podem ser proporcionados no processo de realização de uma AIE?

Resultados de pesquisas, realizadas pelos autores deste artigo, sobre a aprendizagem docente de um grupo de professoras dos anos iniciais no processo de realização de uma Atividade Investigativa de Ensino contribuem com a discussão dessa questão. Tais resultados mostram que os principais modos de aprendizagem criadas ao longo de uma AIE consistem nas variadas ações destinadas a planejar, desenvolver e refletir, oriundas de necessidades geradas mediante à busca de soluções para o problemas de ensino eleito e delimitado pelo coletivo de professoras (AZEVEDO, 2008; AZEVEDO; ABIB, 2013).

O episódio, apresentado a seguir, extraído da AIE Arco-íris na escola, foco de estudo da pesquisa referenciada acima, exemplifica uma dessas ações. O grupo de professoras em formação contínua na escola, após decidirem ensinar sobre o arco-íris para crianças do primeiro ano de escolarização, delimitam seus objetivos e decidem pelo conteúdo do problema de ensino - como podemos levar crianças a aprender sobre a formação do arco-íris? Mobilizado pelo motivo implícito nesse problema, planejou ações, estudou sobre os conceitos envolvidos e vivenciou algumas das ações planejadas. O desafio seguinte foi a elaboração do problema de aprendizagem, aquele que orienta as ações dos estudantes na Atividade Investigativa de Aprendizagem. Esse é o conteúdo e o objetivo da conversação entre as professoras do referido grupo em reunião de planejamento, explícito no episódio apresentado abaixo, extraído da gravação em áudio da reunião das professoras com a coordenadora Nara da área de ciências da escola (os nomes referidos são fictícios).

1. Nara - Vamos à problematização, então. [...]

2. Paula - A gente pode perguntar como se forma um arco-iris e depois usar a folba colorida, não é?

3. Violeta - Como é? Como se forma o arco-íris no cén on o que é o arco-íris?

4. Rosa - O que é um arco-iris é pergunta, mas não parece problema...

5. Flora - É. Acho que o "como se forma" leva a criança a pensar mais. [...] 6. Mirtes - Está bom. O "como se forma" leva a criança a pensar na causa e também na explicação do que é... [...]

7. Nara - Precisamos de um problema mais problema. Esse pode ficar como problema geral do ciclo, mas precisamos de um que gere investigaçöes. Que leve as crianças a querer fazer...

8. Flora - Como podemos fazer um arco-íris, então, não é bom?

9. Nara - Acho que sim. Aqui na escola, não é? É bom delimitar o espaço onde a ação será desenvolvida. Vamos juntar as ideias. O "como se forma o arco-íris no céu" seria o geral, e o outro, decorrente desse, seria "como podemos fazer ou formar o arco-íris aqui na escola". Certo assim? 
Logo no primeiro turno, Nara, a coordenadora/formadora do grupo, enuncia uma pergunta, a qual direciona a conversa para o objetivo pautado. Essa enunciação apenas abriu a conversa, pois os signos ou instrumentos simbólicos mediadores - conhecimentos sobre as características que formam uma questão para que ela se configure como um problema, não foram introduzidos apenas pela formadora, mas também pelas demais professoras. Aliás, o conteúdo desses signos leva a presumir, pela existência de estudos anteriores, a considerar o seu grau de maturidade em relação aos elementos que caracterizam um problema como tal uma pergunta que gere investigações, que faça pensar, que leve a querer fazer, enfatizados nas enunciações das professoras.

A relação de aprendizagem é expressa no processo de comunicação, mais precisamente no compartilhamento dos elementos essenciais que transformam uma pergunta em um problema: o termo como se forma em contraposição ao o que é um arco-íris dá o tom. Rosa, no turno 4, esclarece para Violeta a diferença entre ambos. A coordenadora vai mediando, de modo a complementar e juntar os elementos enunciados. Nota-se que o como se forma vai ganhando corpo como o signo que, somado ao contexto físico, onde a experimentação vai acontecer, configura o problema de aprendizagem: como podemos fazer ou formar um arco-íris aqui na escola?

Perguntamos: por que a conversação entre professoras pode se configurar como um modo de aprendizagem da docência? Primeiro, por ser originada no seio da atividade docente e da necessidade/motivo/objetivo dessa atividade - a criação de oportunidades de apropriação de significados pelos estudantes. Esse é o objetivo que guia a conversação: é preciso encontrar uma pergunta que gere ações de aprendizagem e que coloque os estudantes em atividade. A conversação, tal como uma ação, tem o seu objetivo próprio, mas correlacionado ao objetivo da atividade investigativa de ensino da qual faz parte, qual seja ensinar sobre a formação do arco-íris de modo a garantir a aprendizagem e a apropriação de conhecimentos pertinentes à compreensão desse fenômeno físico.

Em segundo lugar, por se constituir como uma ação coletiva e colaborativa, a qual propicia um campo de relações mediadas, portanto, concebida como prática social. Como tal, estabelece-se como uma ação de aprendizagem no plano verbal e externo, composta por elementos, os quais, no plano interno, como ação mental, podem ser progressivamente apropriados. Esses princípios são coerentes com a lei genética do desenvolvimento cultural elaborada por Vigotski (2010), cuja base encerra a ideia de que o verdadeiro curso do pensamento não vai do individual para o social, mas, ao contrário, do social para o individual, do plano externo e interpsicológico para o plano interno e intrapsicológico.

Em terceiro lugar, porque é possível estabelecer relações entre essa ação externa/social e o desenvolvimento profissional docente, a considerar que a situação destacada, por garantir a cooperação, contempla aprendizagem e, como tal, pode incidir sobre a Zona de Desenvolvimento Proximal das professoras e despertar processos internos de desenvolvimento. Com base em Vigotski (2010), podemos presumir que funções psíquicas relativas à atividade laboral, uma vez apropriadas, se tornam parte das aquisições do desenvolvimento profissional de cada docente em particular.

O conceito de Zona de Desenvolvimento Proximal é constituído por Vigotski (2009) em seu debate sobre distinções entre os processos de aprendizado e desenvolvimento. Esses processos são, com muita frequência, confundidos entre si, quase sempre se fala em aprendizagem e desenvolvimento como se representassem o mesmo processo, ou como processos paralelos que não se inter-relacionam sob nenhum aspecto. Para Vigotski (2010) não é bem assim, pois 
[...] aprendizado não é desenvolvimento; entretanto o aprendizado adequadamente organizado resulta em desenvolvimento mental e põe em movimento vários processos de desenvolvimento que, de outra forma, seriam impossíveis de acontecer. Assim, o aprendizado é um aspecto necessário e universal do processo de desenvolvimento das funções psicológicas culturalmente organizadas e especificamente humanas (VIGOTSKI, 2010, p. 103).

Embora aprendizado e desenvolvimento sejam processos distintos entre si, o desenvolvimento requer ações de aprendizagem para se consubstanciar como tal. O processo de desenvolvimento consiste em aquisições ou apropriações mentais que ocorrem no plano interno, as quais não aconteceriam sem o impulso das ações sociais configuradas como situações de aprendizagem. Entretanto, as funções que se internalizam são as que se encontram em processo de maturação, chamadas por Vigotski (2010, p. 98) de "brotos" ou "flores" do desenvolvimento, em vez de "frutos do desenvolvimento".

Por suposto, a elaboração do problema de aprendizagem situa-se como uma função em processo de formação na ZDP de cada professora, a qual, uma vez, impulsionada pela conversação ou situação de cooperação, pode vir a ser apropriada, a considerar a realização do objetivo proposto objetivado no problema elaborado. Presume-se, portanto, que os signos ou instrumentos mediadores da conversa estão sendo adquiridos no plano verbal para depois serem interiorizados progressivamente como ações mentais. É o que nos diz Leontiev (1978, p. 188), de acordo com as premissas vigotskianas:

Assim, a aquisição das ações mentais, que estão na base da apropriação pelo indivíduo da "herança" dos conhecimentos e conceitos elaborados pelo homem, supõe necessariamente que o sujeito passe das ações realizadas no exterior às ações situadas no plano verbal, depois a uma interiorização progressiva destas últimas; o resultado é que estas ações adquirem o caráter de ações intelectuais estreitas, de atos intelectuais.

Abrimos um parêntese para esclarecer sobre o conceito de internalização, repetido algumas vezes nos termos de apropriação, aquisição das ações mentais e interiorização progressiva, os quais são sinonimamente adotados na perspectiva teórica que os fundamenta - materialismo histórico e dialético. Smolka (2000) discute o conceito de apropriação a partir da elaboração de Marx e Engels, de modo a justificar esse conceito como um processo que supera o tomar posse sobre determinado instrumento ou tomá-lo como seu, mas como modo de usar o instrumento a partir de sua inserção em práticas sociais, o que implica em transformações recíprocas, tanto no objeto, como nos sujeitos envolvidos. Nessa compreensão, apropriação e objetivação são conceitos relacionados: o instrumento produzido tem em si objetivado o elemento cultural humano, o qual é apropriado pelo sujeito.

Ao voltarmos nossa atenção mais uma vez para a conversação entre as professoras, podemos concluir que o processo de desenvolvimento profissional docente pode ser deduzido a partir do processo de apropriação dos instrumentos simbólicos apresentados. Esses conceitos parecem pertencer ao coletivo, pois as professoras conseguem pensar e elaborar com eles - o domínio sobre o uso desses instrumentos simbólicos, bem como, sua objetivação no problema 
de aprendizagem elaborado, não são senão indícios de que sujeitos e objeto estão em processo de transformação.

Contudo, essa apropriação/aquisição não está isolada de outras igualmente importantes para professores que pretendem organizar o ensino por meio de atividades investigativas. Saber formular um problema, embora fundamental, não é suficiente, pois a mediação do processo de aprendizagem em sala de aula, como as ações reflexivas sobre os resultados observados são substancialmente importantes para maturação de novas funções psíquicas. No campo da organização do ensino, as ações reflexivas cumprem o papel de avaliar e validar o que foi planejado pelas próprias professoras, além de lhes proporcionarem significativa possibilidade de refletirem sobre seus processos de aprender a ensinar.

Essas apropriações foram abordadas na pesquisa supracitada como "elaboração de saberes docentes", agora compreendidas, não apenas na dimensão da aprendizagem docente, mas como elementos ou funções que podem compor o desenvolvimento profissional docente. Estudos sobre saberes docentes realizados por autores como Azzi (2005), Garcia (1995) e Tardif (2005), entre outros, possibilitaram a análise das ações realizadas pelas docentes em formação e a conclusão que abordou, além das contribuições da AIE para a elaboração de saberes, a caracterização desses saberes como elementos relacionados a indicadores de funções psíquicas relativas à atividade laboral, como: auto-organização e autoformação docente, hábitos de estudos e pesquisas, planejamento e elaboração das ações condizentes com o ensino de Ciências por investigação, atribuição de sentido às práticas coletivas e colaborativas na escola, entre outros.

\section{Atividade Investigativa de Aprendizagem}

e a apropriação de conhecimentos pelos estudantes

Os pressupostos apresentados para a aprendizagem e desenvolvimento docente são também válidos para discutir os processos de desenvolvimento de crianças desde o seu nascimento, por conseguinte, de estudantes sob ação da educação escolar. Ainda com relação à dimensão teórica aqui adotada, consideramos a Atividade Investigativa de Aprendizagem como uma atividade de estudo, concebida por Leontiev (1991) como dominante no estágio escolar da criança e/ou adolescente. Lógico, isso se deduz, ao se considerar que o estudante está em atividade de estudo, isto é, que seus motivos foram gestados no ambiente escolar de modo a coincidir com o objetivo da atividade da qual ele faz parte.

Vamos retomar a cena apresentada no prólogo para dar continuidade à discussão:

Crianças e professora sentadas em círculo conversam sobre o corpo de uma formiga recém-vista ao estereomicroscópio com aumento de 40x. Palavra vai, palavra vem, uma das crianças enuncia uma pergunta: - Prô, por que a formiga, com seis perninhas, consegue subir na parede, e nós, com duas, não conseguimos?5

Professora e crianças em atividade de ensino e de aprendizagem, respectivamente: em sua ação de ensinar, a professora medeia a resolução de um problema de aprendizagem. Uma

\footnotetext{
${ }^{5}$ Transcrição de arquivos de áudio de 2014 (arquivos pessoais da primeira autora).
} 
roda de conversa, organizada de modo que uma criança veja a outra sempre de frente, gestada socialmente para garantir a oportunidade de falar, de ouvir e de ser ouvida, cujo destaque é o caráter de ação conjunta com forte indício de comunicação. Outro aspecto a ressaltar na organização da aula, é a introdução do estereomicroscópio, como instrumento material a mediar a melhor visualização dos detalhes anatômicos do corpo de uma formiga.

Ações coletivas sob esse caráter se formam ao longo da espiral de aprendizagem, coerente com pressupostos vigostskianos que explicam a relação estabelecida entre a aprendizagem e desenvolvimento psíquico. Para Vigotski (2010, p. 100), “[...] o aprendizado humano pressupõe uma natureza social específica e um processo através do qual as crianças penetram na vida intelectual daqueles que as cercam".

Uma conversação entre professora e estudantes pode ser concebida como prática social, repleta de relações mediadas, por conseguinte, configura-se como uma ação de aprendizagem, supostamente propulsora da apropriação dos instrumentos material e simbólicos presentes. Tal como uma ação social, pode ser progressiva e lentamente transformada numa ação mental.

A pergunta "por que a formiga, com seis perninhas, consegue subir na parede, e nós, com duas, não conseguimos?" informa-nos sobre o assunto da aula, mais que isso, sobre o núcleo conceitual do problema de aprendizagem, considerado como signo ou instrumento simbólico interposto nas relações pela professora. O querer saber demonstrado pela criança, além de evidenciar o seu motivo, indica um processo de apropriação - a criança usa esse conceito ao estabelecer relações de comparação entre a estrutura do corpo de uma formiga e a do corpo de um ser humano e entre a destreza da formiga em subir paredes e a não destreza do ser humano. Entretanto, ela solicita uma argumentação que justifique tal destreza, ou seja, a criança pôs o conceito em movimento e o inseriu na atividade social em realização, isto é, na conversação estabelecida. Além do mais, ao perguntar, ela demonstra que sabe quantas pernas tem a formiga, o que não deixa de ser uma ação mental internalizada, ainda que bastante simples, significativa para o estágio escolar em pauta. Desse modo, o processo de apropriação criou condições de transformações recíprocas entre o objeto e sujeitos envolvidos, entre eles, a professora. Não nos esqueçamos de que a professora é também um sujeito em transformação e em aprendizagem na lida por transformar o seu objeto de trabalho - o estudante em desenvolvimento.

Há coerência entre esses pressupostos é o que nos diz Smolka (2009, p. 8) em sua convicção de que ações intelectuais no plano interno apenas são possíveis a partir da relação com o outro, pela apropriação ou "conversão das relações sociais em funções mentais".

Entretanto, relembramos que esse processo de apropriação não resulta da simples relação que a criança estabeleceu com o objeto, ou apenas da oportunidade de visualizar a formiga no estereomicroscópio, ou ainda, da conversação estabelecida. Há aqui dois aspectos que merecem nossa atenção: primeiro que o conceito relacionado à estrutura anatômica do corpo da formiga não se constitui apenas do número de patas que a identifica como um inseto. Diríamos que ele é insuficiente por se tratar de um pseudoconceito, como diz Vigotski (2009), da aparência do verdadeiro conceito - o sistema conceitual estruturado em seus diferentes nexos. De acordo com esse pensador, a apropriação conceitual em crianças não alcança tão alto grau de desenvolvimento, o qual limita-se ao nível do pseudoconceito, nem de longe desprezível na formação intelectual desses pequenos sujeitos.

O segundo aspecto refere-se a uma importante ressalva delimitada por Vigotski (2009) sobre o processo de apropriação. Esse autor deixa claro que as funções psicológicas superiores 
ou o sistema de funções intelectuais intramentais não são cópias simples e diretas das funções intermentais ou sociais, pois há uma transformação no processo de formação no plano interno da consciência. Essa transformação resulta de uma série de eventos ocorridos ao longo do desenvolvimento. "O processo, sendo transformado, continua a existir e a mudar como uma forma externa de atividade por um longo período de tempo, antes de internalizar-se definitivamente" (VIGOTSKI, 2010, p. 58). Portanto, reafirmamos o caráter processual da apropriação ou desenvolvimento intelectual da criança, ao elaborar e proferir sua pergunta.

Enfim, esses pressupostos de aprendizagem e de desenvolvimento nos alertam para a relevância do papel delegado ao ensino no desenvolvimento intelectual dos sujeitos. Não apenas na criação de ações de aprendizagem, mas no desafiante papel de gestar motivos ou de atrair os estudantes para a atividade de aprender.

É na escola, por meio das ações de aprendizagem criadas pelos professores no âmbito de sua atividade de ensino, que os estudantes têm acesso à cultura elaborada, aos conhecimentos científicos. Para Vigostki (2010), as ações de aprendizagem no âmbito da educação escolar têm potencial de incidência sobre a Zona de Desenvolvimento Proximal de cada estudante e, assim, podem promover o desenvolvimento. A indicativa, portanto, é que o ensino seja voltado para essas funções, para aquelas questões ou conteúdos condizentes com o que o estudante ainda não sabe, mas que pode vir a saber com a realização de ações coletivas sob orientação de adultos ou companheiros mais capazes. Como já foi dito, sem aprendizagem não há desenvolvimento, pois, como assinala Vigotskii (1991, p. 115) “[...] a aprendizagem é um momento intrinsecamente necessário e universal para que se desenvolvam na criança essas características humanas não-naturais, mas formadas historicamente".

Por fim, relembramos o conceito de Atividade Investigativa de Aprendizagem, como um conjunto de ações de aprendizagem que correspondem à intenção do professor, organizada de forma sistemática, para realizar o seu objetivo/motivo de criar ações de aprendizagem, portanto de cunho social, capazes de ativar e promover o desenvolvimento das funções psíquicas de seus alunos.

\section{Considerações finais}

Para finalizar, enfatizamos três aspectos relativos ao caráter organizativo e formativo da Atividade Investigativa de Ensino: primeiro reforçamos o seu potencial de articulação das ações de planejamento, execução e reflexão eminentes à atividade docente, o qual lhe confere o status de unidade do processo de ensino e aprendizagem, melhor dito, o status de práxis pedagógica. A combinação dessas ações dirige a atividade docente para o objeto da docência que é a aprendizagem e desenvolvimento psíquico dos estudantes.

Outro aspecto em destaque é o seu caráter mediador, o qual se constitui como elemento essencial das ações de aprendizagem, explicadas senão como processos resultantes de relações mediadas com grande variedade de instrumentos e signos interpostos entre o sujeito e o seu objeto de trabalho e/ou estudo. Entre esses signos, ressaltamos a linguagem como principal elo intermediador nas relações de comunicação, imprescindíveis aos processos inerentes ao ensino e à aprendizagem. Signos e instrumentos fundem-se no papel da linguagem para mediar o desenvolvimento humano em qualquer estágio, no qual o sujeito se encontre. 
Por fim, chamamos a atenção para a abordagem metodológica da Atividade Investigativa de Ensino, adotada neste artigo, como instrumento mediador da formação de professores e de futuros professores. Exploramos o seu papel metodológico na formação contínua de professores com alcance para a organização do ensino e da práxis pedagógica pari passu à realização da docência. Mostramos a AIE, não apenas como instrumento de organização do ensino, mas também como criadora de ações de aprendizagem da docência propulsoras do desenvolvimento profissional docente. Contudo, deixamos uma pergunta para futuros aprofundamentos: Qual o potencial metodológico da AIE para a formação de futuros professores, isto é, em cursos de licenciatura, particularmente, em disciplinas que orientam estágios supervisionados? Seria a AIE, uma opção metodológica para organizar e orientar projetos de estágios?

\section{Referências}

AZEVEDO, M. N. Ensinar ciências e pesquisa-ação: saberes docentes em elaboração. Jundiaí: Paco Editorial, 2013a.

AZEVEDO, M. N. Mediação discursiva em aulas de ciências: motivos e sentidos do desenvolvimento profissional docente. 2013. Tese (Doutorado em Educação) - Faculdade de Educação, Universidade de São Paulo, São Paulo, 2013b.

AZEVEDO, M. N. Pesquisa-ação e atividades investigativas na aprendizagem da docência em ciências. 2008. Dissertação (Mestrado em Educação) - Faculdade de Educação, Universidade de São Paulo, São Paulo, 2008.

AZEVEDO, M. N.; ABIB, M. L. V. S. Pesquisa-ação e elaboração de saberes docentes em ciências. Investigações em Ensino de Ciências, Porto Alegre, v. 18, n. 1, p. 55-75, 2013.

AZEVEDO, M. N. et al. Crianças e professores em situações de aprendizagens: investigando e aprendendo com os animais que vivem em nossa escola. In: CONGRESSO MUNICIPAL DE EDUCAÇÃO DE SÃO PAULO, 4., São Paulo. Anais... São Paulo: SME, 2005. p. 331-334.

AZZI, S. Trabalho docente: autonomia didática e construção do saber pedagógico. In: PIMENTA, S. G. (Org). Saberes pedagógicos e atividade docente. São Paulo: Cortez, 2005. p. 35-60.

COUTO, M. A rosa caramela. In: COUTO, M. A menina sem palavra: histórias de Mia Couto. São Paulo: Boa Companhia, 2013. p. 17-30.

GARCIA, C. M. El desarrollo profesional de los profesores. In: GARCIA, C. M. Formación del profesorado para el cambio educativo. Barcelona: EBU, 1995. p. 313-380.

KOSIK, K. A dialética do concreto. Rio de Janeiro: Paz e Terra, 1976.

LEONTIEV, A. N. Uma contribuição à teoria do desenvolvimento da psique infantil. In: VIGOTSKI, L. S.; LURIA, A. R.; LEONTIEV, A. N. Linguagem, desenvolvimento e aprendizagem. São Paulo: Edusp: Icone, 1991. p. 59-84. 
LEONTIEV, A. N. Actividad, consciencia y personalidad. Havana: Pueblo y Educación, 1983.

LEONTIEV, A. N. O desenvolvimento do psiquismo. Lisboa: Livros Horizonte, 1978.

MARX, K. O capital: volume 1. São Paulo: Nova Cultural, 1985.

MOURA, M. O. O educador matemático na coletividade de formação: uma experiência com a escola pública. 2000. Tese (Livre Docência) - Faculdade de Educação, Universidade de São Paulo, São Paulo, 2000.

MOURA, M. O. et al. Atividade orientadora de ensino: unidade entre ensino e aprendizagem. Revista Diálogo Educacional, Curitiba, v. 10, n. 29, p. 205-229, 2010.

SÁNCHEZ VÁZQUEZ, A. Filosofia da práxis. São Paulo: Expressão Popular, 2007.

SAVIANI, D. Educação: do senso comum à consciência filosófica. 13. ed. Campinas: Autores Associados, 1996.

SMOLKA, A. L. B. A atividade criadora do homem: a trama e o drama (apresentação). In: VIGOTSKI, L. S. Imaginação e criação na infância. São Paulo: Ática, 2009. p. 7-10.

SMOLKA, A. L. B. O (im)próprio e o (im)pertinente na apropriação das práticas sociais. Cadernos Cedes, Campinas, v. 20, n. 50, p. 26-40, 2000.

TARDIF, M. Saberes docentes e formação profissional. Petrópolis: Vozes, 2005.

VIGOTSKI, L. S. A construção do pensamento e da linguagem. São Paulo: WMF Martins Fontes, 2009.

VIGOTSKII, L. S. Aprendizagem e desenvolvimento intelectual na idade escolar. In: VIGOTSKII, L. S.; LURIA, A. R.; LEONTIEV, A. N. Linguagem, desenvolvimento e aprendizagem. São Paulo: Edusp: Icone, 1991. p. 103-118.

VIGOTSKI, L. S. A formação social da mente: o desenvolvimento dos processos psicológicos superiores. São Paulo: Martins Fontes, 2010.

Artigo recebido em 12/05/2017. Aceito em 18/10/2017.

Contato: Universidade Federal de São Paulo, Rua Antonio Doll, Centro, Diadema, SP, CEP 09920-540, Brasil. 